\title{
Pesquisa, ensino e sociedade: ampliando conhecimentos na área das Ciências Farmacêuticas
}

\author{
Research, teaching and society: expanding knowledge in the \\ Pharmaceutical Sciences field
}

\author{
Anselmo Gomes de OLIVEIRA; \\ Dâmaris SILVEIRA \\ Editores-chefe
}

Ao participar de uma sociedade multicultural e globalizada, o objetivo de cada cidadão não é apenas discutir os aspectos que o rodeiam, mas fazer parte de tudo o que é importante para a humanidade. Contudo, aspectos básicos do cotidiano ainda continuam em pauta, por exemplo, a Ciência, em todas as suas vertentes, e que papel ela deve desempenhar para a melhoria da vida em nosso mundo, mesmo que, em alguns casos, o avanço científico nem sempre é realizado com finalidades benéficas.

O principal papel da ciência no mundo contemporâneo é gerar conhecimentos avançados que permitam a antecipação dos fundamentos para a resolução dos problemas qu se apresentem. Muitos cientistas fizeram e fazem disso o principal objetivo de suas vidas, permitindo o estabelecimento de uma relação muito forte entre a Ciência e a Sociedade.

Assim, a pesquisa científica é um dos caminhos que tem promovido, para a humanidade, o entendimento da realidade do mundo, sendo um instrumento importante para impulsionar o desenvolvimento, não só tecnológico, mas também social.

A pesquisa e o desenvolvimento científicos ( $\mathrm{P}$ \& D), tanto em seus aspectos básicos como aplicados, constituem as principais fontes de geração de conhecimento e de criatividade, indispensáveis para a melhoria da qualidade de vida em sociedade. Tal fato é mais visível nos países mais desenvolvidos, nos quais as condições da $\mathrm{P} \& \mathrm{D}$ são mais favoráveis e alavancadas por investimentos proporcionais ao desenvolvimento desejado.
No Brasil, a principal fonte de produção de P\&D esta enraizada nas Universidades, principalmente as Públicas, as quais possuem um elo indissociável entre Ensino, Pesquisa e Extensão. Das Universidades é esperado que além da produção de conhecimentos avançados, também sejam formados profissionais capazes de atuar dignamente no mercado de trabalho, de forma que, como consequência, a sociedade possa se beneficiar intensamente dessas conquistas.

No contexto P \& D, o periódico Infarma Ciências Farmacêuticas está situado na interface, e foi estruturado para disseminar os conhecimentos científicos gerados no campo das Ciências Farmacêuticas e áreas correlatas. $\mathrm{O}$ campo das Ciências Farmacêuticas é amplo, as possibilidades de disseminação de conhecimentos são reais e a criatividade faz parte do potencial de nossos colaboradores. A cada ano são publicados quatro números regulares, contendo artigos originais, revisões críticas e notas técnicas. Além disso, eventualmente, números especiais ou suplementos são publicados, atendo a um tema determinado.

Neste número 2, do volume 31 de 2019, os artigos publicados transitam por várias áreas das Ciências Farmacêuticas. Contudo, vários dos artigos passam pela gestão e pelos cuidados farmacêuticos. Assim, na nota técnica Construção de um modelo de evolução farmacêutica em prontuário médico, os autores propõem uma documentação padronizada dos cuidados farmacêuticos, para a otimização da farmacoterapia do paciente e a melhoria da comunicação nas equipes multiprofissionais, deindo 
quais informações são relevantes e como organizá-las, utilizando o sistema Subjetivos-Objetivos-Avaliação-Planejamento (SOAP). Os leitores também terão oportunidade de ler o artigo Assistência Farmacêutica na atenção primária à saúde de um Município Potiguar, de autoria de Bernardino e Batista, um estudo transversal e descritivo do uso de 10 indicadores aplicados à Central de Abastecimento Farmacêutico e 30 aplicados em 23 farmácias de Unidades Básicas de Saúde, mostrando que ainda há necessidade de maior responsabilidade e compromisso dos gestores municipais para serem mais efetivas. No artigo Estruturação de um Serviço de Informações sobre Medicamentos (SIM) em um hospital do Rio Grande do Norte, Brasil, de autoria de Martins e Batista, o objetivo foi avaliar as informações prestadas por um Serviço de Informações sobre Medicamentos de um Hospital Regional e seu papel na redução do uso irracional de medicamento. Viana e colaboradores abordaram, em Descarte de medicamentos: conhecimento e prática de estudantes de farmácia no Brasil, o conhecimento e a prática das vias corretas do descarte de medicamentos por estudantes de Farmácia mostrando que a maioria dos estudantes do início do curso descartam medicamentos vencidos ou não utilizados de forma ambientalmente incorreta, mas que, com a evolução do curso, o cuidado com o descarte tende a se tornar significativamente mais importante.

Além desses, duas revisões sobre Nutrição e Saúde, A deficiência de tiamina e niacina como fator de risco para doenças neurológicas, e Kombucha: efeitos in vitro $\boldsymbol{e}$ in vivo, são exemplos da abrangência da atuação farmacêutica.

Assim, convidamos nossos leitores e colaboradores para uma imersão nos assuntos apresentados nesse número de Infarma-Ciências Farmacêuticas. Certamente os temas podem contribuir para a ampliação de nossa cultura multiprofissional na área das Ciências Farmacêuticas. Ainda, convidamos a todos a colaborarem com a divulgação das Ciências Farmacêuticas, enviando seus artigos para os próximos números do periódico. 